\title{
Research and development of designs of the equipment for classifying the materials with particles
}

\author{
Ganbaatar Gunsen*iD, Renchinvanjil Yadam \\ School of Mechanical engineering and Transportation, Mongolian University of Science and Technology, Chinggis Avenue \\ 17033, Ulaanbaatar, Mongolia
}

*Corresponding author: gbr_0707@ must.edu.mn

https://orcid.org/0000-0002-9323-0520

\begin{tabular}{lll}
\hline Received: 30.03.2021 & Revised: 02.06.2021 & Accepted: 15.09.2021 \\
\hline
\end{tabular}

\begin{abstract}
There are studies showing that $10 \%$ of the total energy generated in the world is spent on crushing and sifting and sorting processes in agricultural and mining sectors. 52.7\% of the total mining industries extracts metal ores, $36.3 \%$ of them extracts coal and agricultural sector plants wheat and crops on the 350 thousand hectares of land per year an average. It can be seen that there is a need for sorting the materials with particles in these sectors. According to the needs, the energy expenditure is high and the devices and equipment used still maintaining their traditional designs and makes. The process of sorting out the materials with particles is sifted by the flat surfaced, trommel shaped, and cylindrical mesh surfaces positioned in vertical axis. The above methods are still in use, which becomes the basis of mechanical sifting methods. Therefore, the researchers continue to work on perfecting the above methods. The goal of this research work is to survey and determine the possibility of the changes in the designs of sifting equipment with the trommels can improve the influences that are created during the sifting process, the efficiency of sifting and the productivity of device or equipment. By this research work, with the purpose to improve the parameters of sifting of materials with particles, we will change the design of cylindrical trommel of the cross trommel sieve, which is often used in the sifting process to axle to its axis, and in order to confirm the results of experiment by determining the CAD analysis of axle trommel and the movement of one particle inside of it using the ADAMS software, the experiment on the real equipment shall be rationalized by putting into the mathematic modeling, develop the physical modeling using the "EDEM solution" software and process the results.
\end{abstract}

Keywords: sifting, trajectory, sieves, comparing angles, results

\section{Introduction}

Granular and powder materials classification and sifting processes are used in many fields such as energy, mining, pharmaceutical, food and chemical technology, agricultural, building materials, waste processing plants, etc. The particles of materials have different types of shapes, mixed and the sizes are different. Sifting of particle materials consists of separating mixed particles, determining the properties of interactions, and the laws of particles and particles mass shifting. Also, correctly planning the features of physical and mechanical designs of rotating trommels and the properties of the materials included in it shall provide the condition for operating the mechanism. The most efficient method to make the screening process rational is using the mathematical modeling. I assume that using the mathematical modeling defines the rational method of screening process, moreover, it is possible to reduce the number parameters of the experiments to be conducted to determine the reactions from the invented mechanical system during the screening process. It has proven that determining the mass movement law of materials with particles based on the discrete element method (DEM) developed by Cundall and Strack is efficient. [1][2][3]. In other words, when applying the same amount of forces to particle materials that differ in density, weight and size, some of them are mixed and some are distinguished. Many different types of the movements of the flows of particles inside of the 
such as sliding, rolling, hitting, and centrifuge affect the efficiency of screening [4][5][6]. It was determined that the particles moving inside of the trommel are not only in the dry condition, but also in the humid and wet environment and it greatly affect to the movement features or properties; the particle materials move with high speeds harmonizing with the liquid and free surface shall be limited by the extent of trommel [7][8]. In 2001, the researchers Mellmann et al determined surveying the filling angle and the wall friction coefficient of the particle materials. [9]. Also, they have determined that the state of the granular material is correlated to the rotation speed of trommel, the size of the filling, and the size of particles by the experiment [10] [11]. It

\section{Changes due to the trommel's axial angle}

It was assumed, during the survey of the parameters such as trajectory, speed and acceleration of movement of particles moving inside of the trommel screen, and the movement activations of the material layers, that the main factors affecting them were the trommel's axial angles, rotations, and frequency and was surveyed using the experiment and determined the relationship between the rotation of the wheat particle materials and the sharp drop angles in the trommel system spinning by the horizontal axis [12] [13][14]. In addition, they have conducted the researches to distinguish the particles by the liquid flows and determine the particle sizes sorted out from the trommel screen relating to the design peculiarities [15]. B.Bellocq et al have conducted the survey to improve the efficiency of the trommel screen with multi layers [16]. Looking at the event that the method leaning to the basic axis of trommel is still maintained, it was assumed that it is required to conduct additional surveys and researches furthermore.

conducted the CAD experiment. The following picture shows trommel axis as it is rotating around the $\mathrm{Y}$-axis.

By the above experiment, the axial trommel results to the volume changes in virtual type and it was shown in the following table.
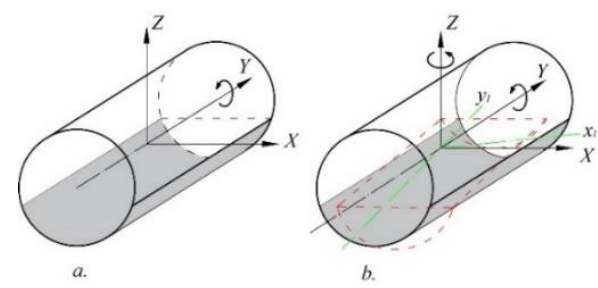

Pigure 1. a. Traditional position b. Axial position

Virtual changes of sifting surface areas and the volumes

Table 1

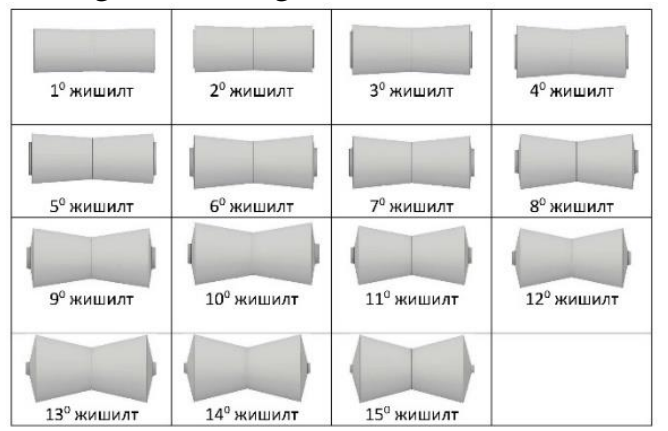

Virtual experiment results

\begin{tabular}{ccccc}
\hline No. & Axial angle $^{\circ}$ & Area sq.m. & Volume cub. m. & S working area \% \\
\hline 0 & 0 & 0.415 & 0.0218 & - \\
1 & 1 & 0.424 & 0.0228 & $2.1 \%$ \\
2 & 2 & 0.432 & 0.0238 & $4.09 \%$ \\
3 & 3 & 0.44 & 0.025 & $6.02 \%$ \\
4 & 4 & 0.448 & 0.026 & $7.95 \%$ \\
5 & 5 & 0.456 & 0.0271 & $9.87 \%$ \\
6 & 6 & 0.464 & 0.0282 & $11.8 \%$
\end{tabular}




\begin{tabular}{ccccc}
7 & 7 & 0.4715 & 0.0293 & $13.6 \%$ \\
8 & 8 & 0.4788 & 0.0303 & $15.37 \%$ \\
9 & 9 & 0.4861 & 0.0314 & $17.1 \%$ \\
10 & 10 & 0.4931 & 0.0325 & $18.8 \%$ \\
11 & 11 & 0.5 & 0.0336 & $20.4 \%$ \\
\hline
\end{tabular}

By conducting this experiment, the change occurring in the virtual dimensions of the screening surface resulted to the assumption that it is required to determine the properties of the motions of particles moving inside of the trommel. Before conducting the next experiment, in 1927, the scientist Levinson L. B. determined the main parameters such as the trommel diameter $D$ and the height $h$ of the loading material in the trommel relating to the maximum diameter $d_{\max }$ of the screening particle material when determining the geometric basic dimensions of the trommel screen. The geometric basic dimensions of the trommel shall be determined using the following correlations:

$$
\begin{gathered}
D \geq 14 \cdot d_{\max } ; \quad h \leq 2 \cdot d_{\max } ; \quad \alpha \leq 1^{0}-\text { ээс } 15^{0} \\
D \geq 210 \mathrm{MM} ; \quad h \leq 30 \mathrm{~mm}, \quad \beta_{\max } \leq 90^{0}
\end{gathered}
$$

Where: $d_{\max }-$ diameter of the material going into the trommel, $\mathrm{mm}$;

$h$ - height of the material to be loaded into the trommel, $\mathrm{mm}$,

$\beta_{\max }-$ degree to be created by the trommel slope with the vertical axis, degrees,

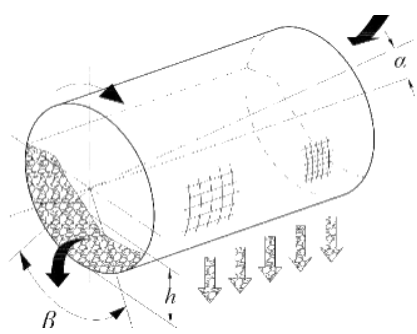

Pigure 2. Basic measurements of trommel

Determining the particle motion properties

The particle motion properties were compared by the motion trajectories' difference between the traditional and compared/installed as axial position of trommel screen. To prove this idea, it was experimented by creating the physical model of the trommel on the MSC-ADAMS software.

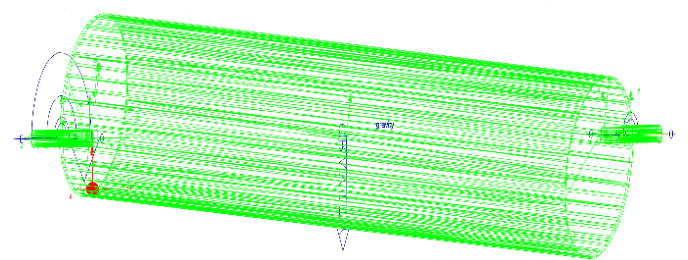

Pigure 3. Physical model of trommel

The experiment was carried out by incorporating the changes in the frequency and angle of rotation of the trommel and the result was a large amount of data parameter and thus, we have included one example by summarizing them.
Using the data parameters obtained from the experiment, the lengths of trajectories of a single particle movement were identified and compared. The graph of the 3-dimensional trajectory of the particles was generated in the MATLAB software. 
The datas generated by the MSC-ADAMS

\begin{tabular}{cccccc}
\hline No. & Time & $\begin{array}{c}\text {.PART_3.CM } \\
\text { Position.X }\end{array}$ & $\begin{array}{c}\text {. PART_3 .CM } \\
\text { P osition. Y }\end{array}$ & $\begin{array}{c}\text {.PART_3.CM } \\
\text { _Position.Z }\end{array}$ & Average \\
\cline { 1 - 2 } \cline { 5 - 7 } & 0 & -323.8 & -67 & $1.84 \mathrm{E}-14$ & 0.0549 \\
2 & 0.0033 & -323.8 & -67.0549 & $1.84 \mathrm{E}-14$ & 0.1634 \\
3 & 0.0067 & -323.8 & -67.2183 & $1.84 \mathrm{E}-14$ & 0.0207 \\
4 & 0.007 & -323.8 & -67.239 & $-2.61 \mathrm{E}-07$ & 0.015143 \\
5 & 0.0079 & -323.7891 & -67.2477 & -0.0059 & 0.040182 \\
6 & 0.01 & -323.7548 & -67.2569 & -0.0247 & 0.080075 \\
997 & 2.3967 & 290.5354 & -148.0089 & -55.1537 & 0.164123 \\
998 & 2.4 & 290.5559 & -147.9924 & -54.9917 & 330.679 \\
& & & & & 1097.094 \\
\hline
\end{tabular}

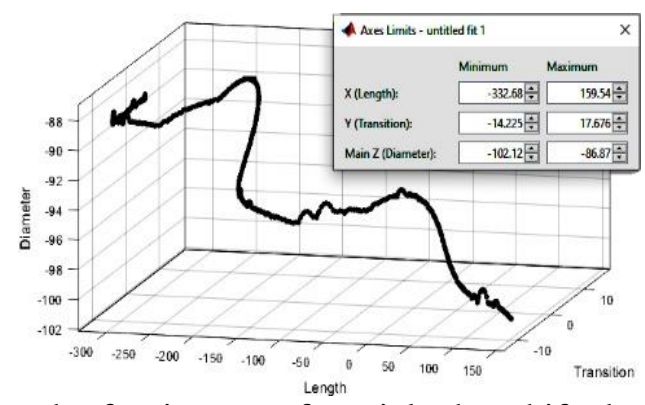

Pigure 4 . The length of trajectory of particle that shifted at maximum level

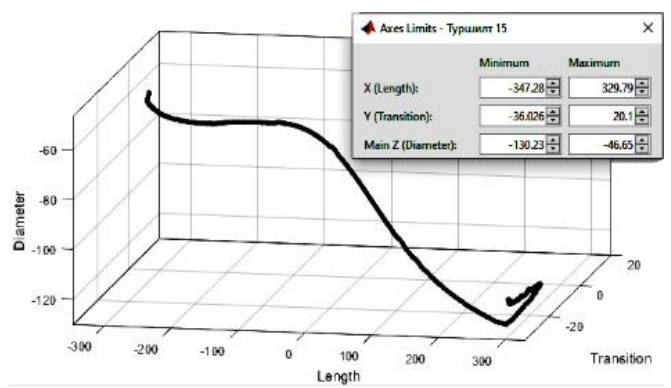

Pigure 5. The length of trajectory of particle shifter at the time of non-comparing

The shift lengths of particles at the time of compared and non-compared state by the 7 degrees of the trommel with the diameter of $210 \mathrm{~mm}$ are shown in the Pictures 3 ба 4 (1097 mm, $983.7 \mathrm{~mm})$. As drawing a conclusion here, it is assumed that the probability to be sifted shall be increased because the

Table 3 


$$
\begin{gathered}
y=1018.25-88.178 \cdot x_{1}+21.84 \cdot x_{2}+80.433 \cdot x_{3}+20.0725 \cdot x_{1} x_{2}+50.5775 \cdot x_{1} x_{3}+8.1725 \cdot \\
x_{2} x_{3}+6.406 \cdot x_{1}^{2}+3.1438 \cdot x_{2}^{2}-66.487 \cdot x_{3}^{2}
\end{gathered}
$$

Basing on the values obtained from the planning sizes has been obtained for further experiments. matrix, the trommel physical model with 5 different

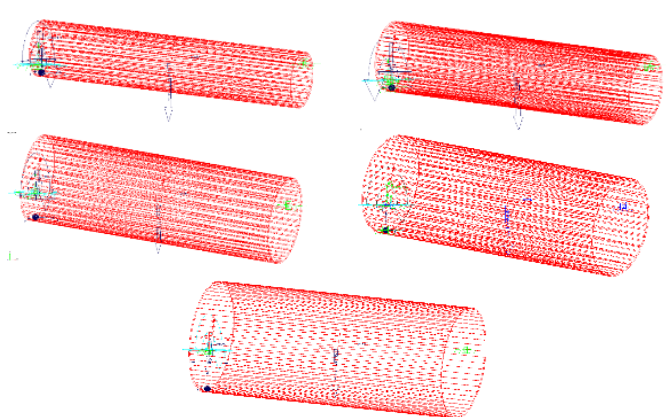

Pigure 6. Physical models of trommels obtained from planning

CAE analyses made on axial trommel screen

The method of using DEM for determining mutual impact between granular-granular, trommel-granular has been widely used in modern research works. The model, initially found by the researchers Gundal and Strack in 1974, and later obtained by Tsui, HertzMidlin, has been widely used.

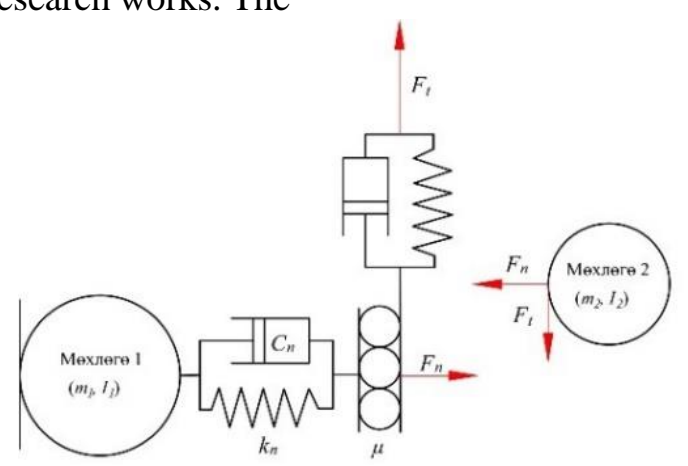

Pigure 7. The model of Tsuji and Hertz-Midlin that improved mutual impacting of granular materials

$$
F_{i j}^{t}=\left(-k_{t} \delta_{i j}^{t}-\eta_{t} v_{i j}^{S}\right)
$$

Here: $v_{i j}^{S}$ - sliding speed at the impacting spot

$v_{i j}^{t}$ - tangential speed

It is considered that the tangential force creates the sliding with each other or on surface. condition for mutually interacting granules for

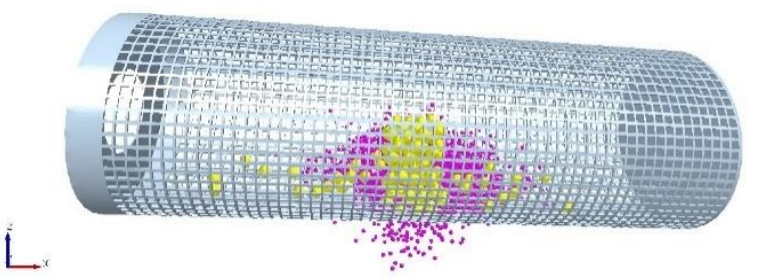

Picture 8. Model for loading material to axial trommel using EDEM program 


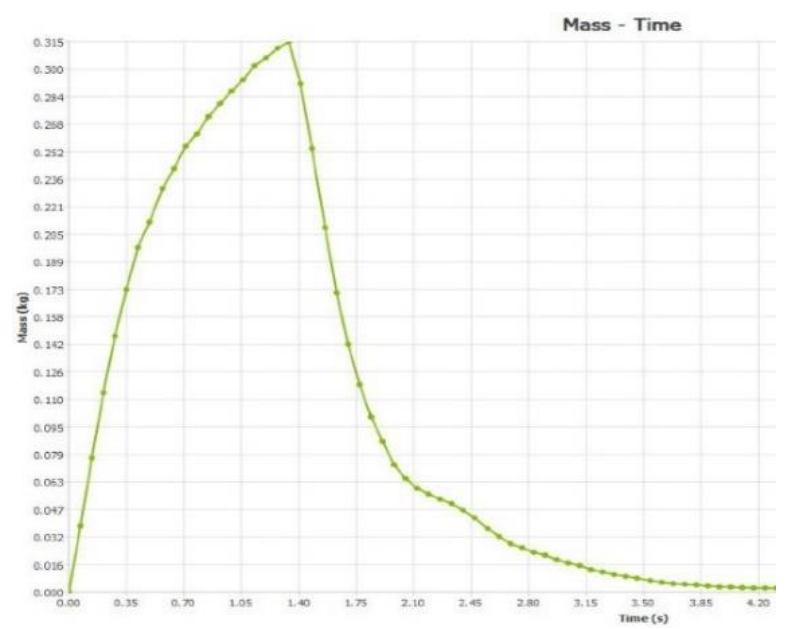

Pigure 9. Emission properties of the material

The results of EDEM analyses have been shown using data and graphs. The gained results show that the axial trommel is more efficient than the

\section{Experiment with axial trommel screen}

Basing on the physical model obtained as a result of traditional trommel. Hence, the experiment has been made on real equipment and approved.

simulation made previously, the axial trommel screen will be invented, and a real experiment shall be launched and the results approved.

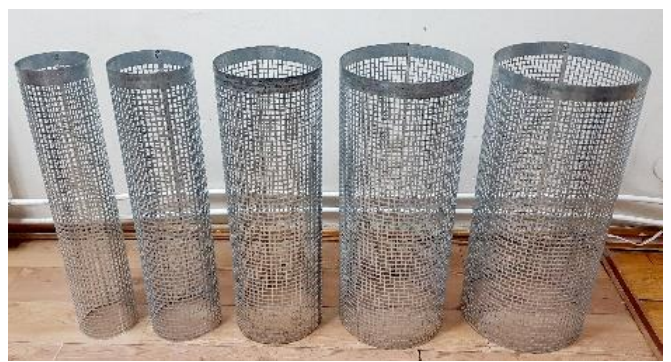

Pigure 10. Created trommel in reality
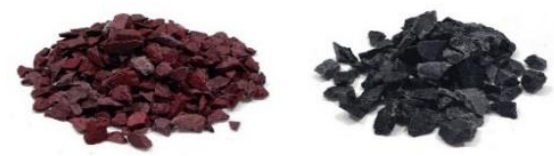

Pigure 11. Materials ready for screening

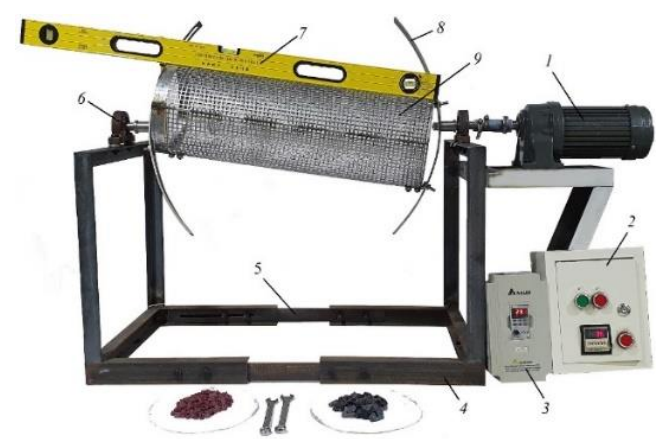

Pigure 12. Axial trommel equipment

1. Electric motor 2. Control block 3. Frequency converter 4. Frame 5. Direct path 6. Bearing 7. Angle gauge 8 Comparator path 9 . Screen trammel 
Table 5

Test results and planning matrix

\begin{tabular}{|c|c|c|c|c|c|}
\hline \multirow{3}{*}{$\begin{array}{l}\text { Experiment`s } \\
\text { no. }\end{array}$} & \multirow{2}{*}{\multicolumn{2}{|c|}{$\begin{array}{l}\text { Standard value of the impacting } \\
\text { factor }\end{array}$}} & \multicolumn{2}{|c|}{ Working matrix } & \multirow{3}{*}{$\begin{array}{c}\text { Average value } \\
\bar{Y}_{u 1}\end{array}$} \\
\hline & & & \multirow{2}{*}{$\frac{\mathrm{N} \text { rotation/min }}{X_{1}}$} & \multirow{2}{*}{$\begin{array}{c}D \text { мм } \\
X_{2}\end{array}$} & \\
\hline & $x_{1}$ & $x_{2}$ & & & \\
\hline 1 & +1 & +1 & 45 & 260 & 160.4 \\
\hline 2 & -1 & +1 & 25 & 260 & 171.4 \\
\hline 3 & +1 & -1 & 45 & 160 & 71.2 \\
\hline 4 & -1 & -1 & 25 & 160 & 78.2 \\
\hline 5 & -1.414 & 0 & 20.86 & 210 & 112.6 \\
\hline 6 & 1.414 & 0 & 49.14 & 210 & 106.2 \\
\hline 7 & 0 & -1.414 & 35 & 139.3 & 49.6 \\
\hline 8 & 0 & 1.414 & 35 & 280.7 & 172 \\
\hline 9 & 0 & 0 & 35 & 210 & 85.4 \\
\hline 10 & 0 & 0 & 35 & 210 & 84.4 \\
\hline 11 & 0 & 0 & 35 & 210 & 84.2 \\
\hline 12 & 0 & 0 & 35 & 210 & 83 \\
\hline 13 & 0 & 0 & 35 & 210 & 86.8 \\
\hline
\end{tabular}

Let us determine the regressive dependence of the experimental results from the input value using
MATLAB program by the tasks of the above experiment.

$$
\begin{gathered}
\mathrm{F}(\mathrm{x})=352.15-10.33{ }^{*} \mathrm{x}-1.66 \cdot * \mathrm{y}-0.002 \\
* \mathrm{x} . * \mathrm{y}+0.15 . * \mathrm{x} .{ }^{\wedge} 2+0.0062 . * \mathrm{y} .{ }^{\wedge}
\end{gathered}
$$

That regressive dependence has come out and the have been determined using the MATLAB code. maximum and minimum screening differing values

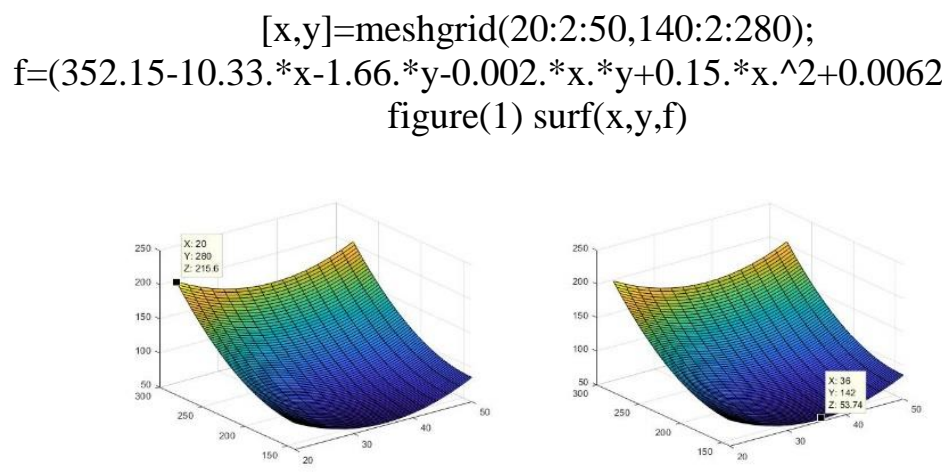

Pigure 13. Maximum and minimum values of the material screening

$$
\begin{aligned}
& \text { function } \mathrm{f}=\text { ganbaafunc }(\mathrm{x}) \\
& \mathrm{f}=(352.53-10.33 \cdot * \mathrm{x}(1)-1.66 \cdot * \mathrm{x}(2)- \\
& \left..0019 . * x(1) . * x(2)+0.15 . * x(1) .^{\wedge} 2+0.0062{ }^{*} x(2) .^{\wedge} 2\right) \text {; } \\
& \text { >> [x, fval]=fminsearch(@ganbaafunc,[20 50;140 } \\
& \text { 280]) }
\end{aligned}
$$

This value is the experimental truth coming out with a slight difference when calculating using the Lagrange's method of the lowest energy, and the

$$
\begin{gathered}
\mathrm{x}_{1}=25.9964, \mathrm{x}_{2}=265.7918: \\
\mathrm{x}=25.9964 ; \\
\mathrm{y}=265.7918 ; \\
\mathrm{f}=(352.15-10.33 * \mathrm{x}-1.66 * \mathrm{y}- \\
\left.0.002 * \mathrm{x} * \mathrm{y}+0.15 * \mathrm{x}^{\wedge} 2+0.0062 * \mathrm{y}^{\wedge} 2\right) ;
\end{gathered}
$$

As a result of the optimization, the minimum value

\section{$\mathrm{x}=$ \\ $35.3155 \quad 25.9964$ \\ $139.2822265 .7918 \mathrm{val}=$ \\ 54.5214}

optimization`s highest value in the regression equation is at

$$
\begin{gathered}
>>f \\
f= \\
167.9462
\end{gathered}
$$

for screening deviated from the real experimental value. 


\section{Conclusion}

The ratio between the axial trommel diameter for launching experiment and length shall be 1:3 whereas axle angle incline shall not overcome 7 degree. The most trajectory of one granule's movement in an axial trommel has been determined as $\mathrm{n}=25$ эрг/мин, $\mathrm{d}=260$ мм, $\alpha=7^{0}$ by making simulation with the main values of the axle trammel in the MSC.ADAMS program. The trajectory of one granule`s movement in an axial trommel shows a

\section{References}

[1] B. C. Burman, P. A. Cundall, and O. D. L. Strack, "A discrete numerical model for granular assemblies," Geotechnique, vol. 30, no. 3, pp. 331-336, 1980, doi: 10.1680/geot.1980.30.3.331.

[2] H. P. Zhu, Z. Y. Zhou, R. Y. Yang, and A. B. $\mathrm{Yu}$, "Discrete particle simulation of particulate systems: A review of major applications and findings," Chem. Eng. Sci., vol. 63, no. 23, pp. 5728-5770, 2008, doi: 10.1016/j.ces.2008.08.006.

[3] L. T. Fan, Y. ming Chen, and F. S. Lai, "Recent developments in solids mixing," Powder Technol., vol. 61, no. 3, pp. 255-287, 1990, doi: 10.1016/0032-5910(90)80092-D.

[4] M. Furuuchi, C. Yamada, and K. Gotoh, "Shape separation of particulates by a rotating horizontal sieve trommel," Powder Technol., vol. 75, no. 2, pp. 113-118, 1993, doi: 10.1016/0032-5910(93)80071-H.

[5] S. H. Chou, H. J. Hu, and S. S. Hsiau, "Investigation of friction effect on granular dynamic behavior in a rotating trommel," $A d v$. Powder Technol., vol. 27, no. 5, pp. 1912-1921, 2016, doi: 10.1016/j.apt.2016.06.022.

[6] D. V. Khakhar, J. J. McCarthy, and J. M. Ottino, "Mixing and segregation of granular materials in chute flows," Chaos, vol. 9, no. 3, pp. 594610, 1999, doi: 10.1063/1.166433.

[7] P. Y. Liu, R. Y. Yang, and A. B. Yu, "DEM study of the transverse mixing of wet particles in rotating trommels," Chem. Eng. Sci., vol. 86, pp. 99-107, 2013, doi: 10.1016/j.ces.2012.06.015.

[8] N. Gui et al., "DEM simulation and analysis of particle mixing and heat conduction in a rotating trommel," Chem. Eng. Sci., vol. 97, pp. 225-234, 2013, doi: 10.1016/j.ces.2013.04.005.

[9] J. Mellmann, "The transverse motion of solids in rotating cylinders-forms of motion and ratio of $18-21 \%$ compared to the one granule's movement in a traditional trommel screen. The result of the granule`s emission coming out from EDEM simulation program is by $18.5 \%$ higher than that of the screen with traditional trommel.

Moreover, the real experimental axial trommel weighs $112 \mathrm{~g}$, and the traditional screen $88.4 \mathrm{~g}$, which shows $26,7 \%$ higher screening efficiency.

transition behavior," Powder Technol., vol. 118, no. 3, pp. 251-270, 2001, doi: 10.1016/S0032-5910(00)00402-2.

[10] B. C. Silvério, K. G. Santos, C. R. Duarte, and M. A. S. Barrozo, "Effect of the friction, elastic, and restitution coefficients on the fluid dynamics behavior of a rotary dryer operating with fertilizer," Ind. Eng. Chem. Res., vol. 53, no. 21, pp. 8920-8926, 2014, doi: 10.1021/ie404220h.

[11] A. C. Santomaso, Y. L. Ding, J. R. Lickiss, and D. W. York, "a Rotating Drum Operated Over a Wide," vol. 81, no. September, pp. 936-945, 2003.

[12] D. A. Santos, M. A. S. Barrozo, C. R. Duarte, F. Weigler, and J. Mellmann, "Investigation of particle dynamics in a rotary trommel by means of experiments and numerical simulations using DEM," Adv. Powder Technol., vol. 27, no. 2, pp. 692-703, 2016, doi: 10.1016/j.apt.2016.02.027.

[13] Y. L. Xiao, E. Specht, and J. Mellmann, "Experimental study of the lower and upper angles of repose of granular materials in rotating trommels," Powder Technol., vol. 154, no. 2-3, pp. 125-131, 2005, doi: 10.1016/j.powtec.2005.04.040.

[14] P. C. Xiangyi Meng, Fuguo Jia *, Hualong Qiu, Yanlong Han, Yong Zeng, Yawen Xiao, "DEM study of white rice separation in an indented cylinder separator." .

[15] D. Höhner, S. Wirtz, and V. Scherer, "A study on the influence of particle shape and shape approximation on particle mechanics in a rotating trommel using the discrete element method," Powder Technol., vol. 253, pp. 256265, 2014, doi: 10.1016/j.powtec.2013.11.023.

[16] “j.jfoodeng.2016.09.023.pdf." . 
Summarized results of the EDEM simulation (graph`s value, 100 lines)

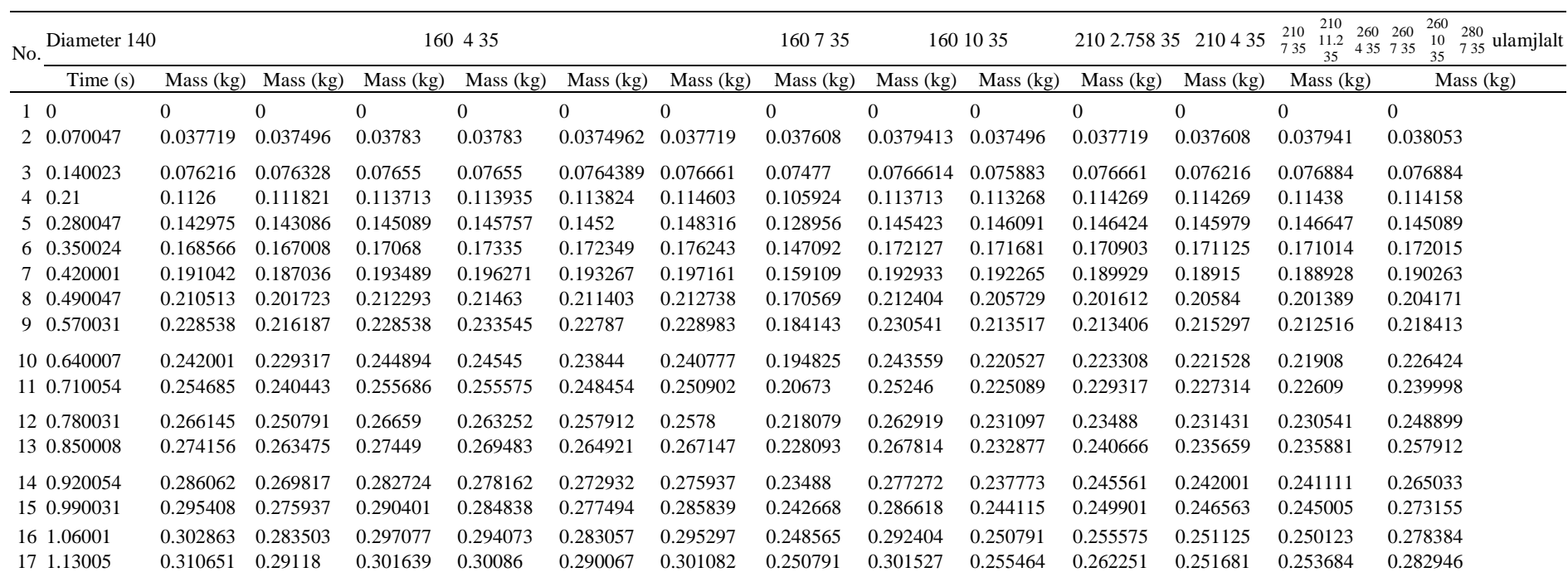

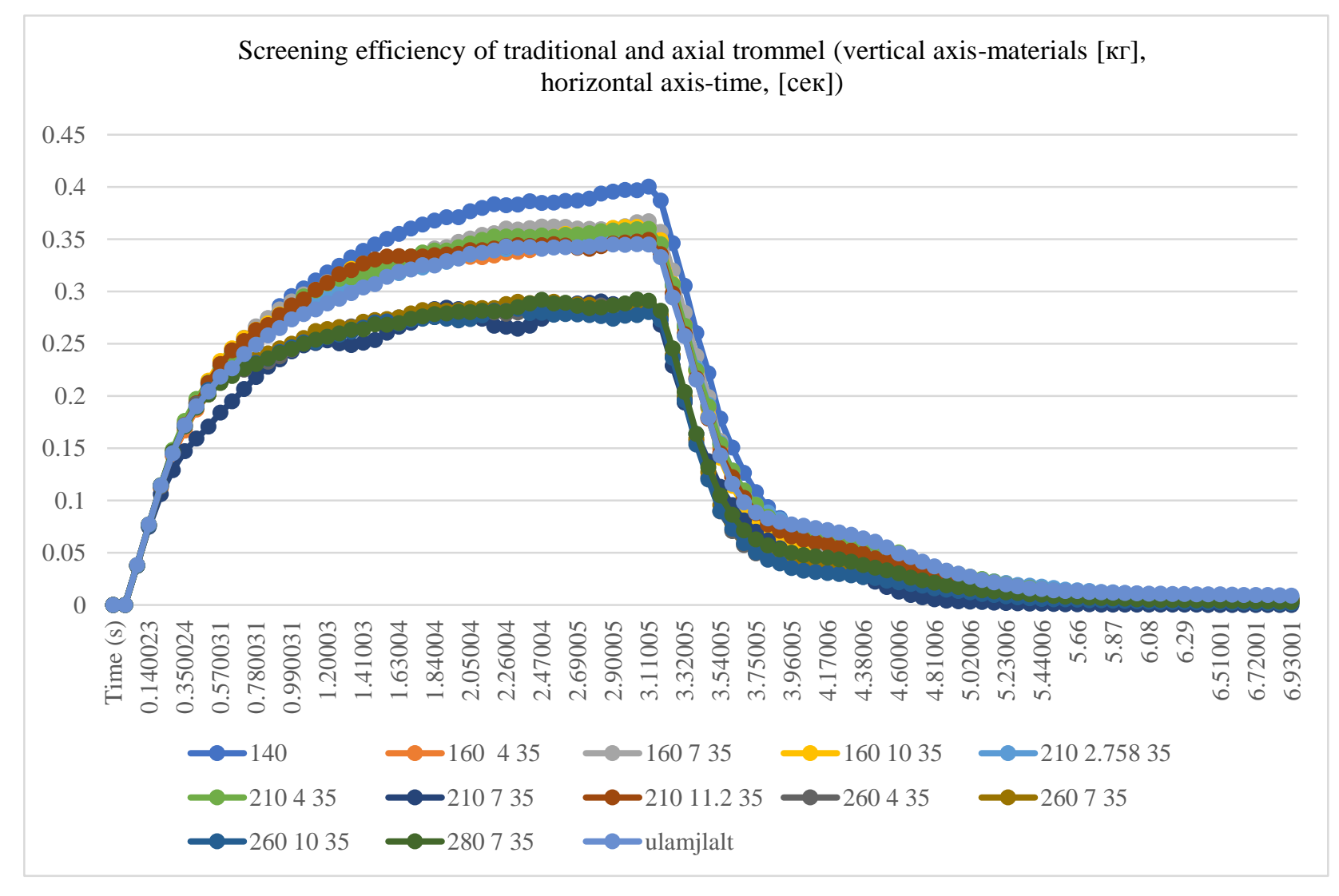

